\title{
Competency-based Medical Education: The Perceptions of Faculty
}

\author{
Shaifaly M Rustagi ${ }^{1}$, Charu Mohan ${ }^{2}$, Niket Verma ${ }^{3}$, Bindu T Nair ${ }^{4}$
}

\begin{abstract}
Introduction: Competency-based medical education (CBME) is being implemented across India in medical colleges from the 2019 batch. The new aspects of this curriculum are introduction of a foundation course (FC); early clinical exposure; longitudinal program on attitudes, ethics, and communication; electives; emphasis on small group learning methods; assessment changes; and most importantly, a horizontally aligned and vertically integrated method of teaching-learning. The faculty members of medical colleges are the prime movers for implementing the CBME. The Medical Council of India ( $\mathrm{MCl})$ is imparting training about the new curriculum to the faculties of all medical colleges across India. All faculty members have not been able to get the requisite training in the latest changes as required for the new curriculum. This study is an attempt to analyze the awareness and perceptions of the faculty and the challenges envisaged in the implementation of CBME.

Materials and methods: All faculty members of our college were e-mailed a self-structured, prevalidated Google questionnaire. The results were analyzed by the inbuilt available Google statistical software.

Results: A total of 58 faculty members responded to the questionnaire. Of the 58 faculty members, $87.9 \%$ were aware about the CBME but only $51.7 \%$ felt that better doctors would be produced as a result of its implementation. Eighty-one percent were aware that small group teaching needs to be two-thirds of the total teaching hours in a particular subject but the small group teaching methods only few could enlist. Around $86.2 \%$ agreed that students should have early clinical exposure. Around $41.4 \%$ were not aware of the changes in internal assessment as proposed by CBME.

Conclusion: The faculty lacked uniformity in awareness and there was ambiguity on various aspects and constituents of CBME as proposed by the $\mathrm{MCl}$. The proper implementation of CBME would require more clarity and continuous efforts by Medical Education Units (MEU) under guidance of the MCl to update their faculty in the form of Curriculum Implementation Support Programs (CISPs), Revised Basic Course Workshops (RBCWs), and advanced courses in medical education.
\end{abstract}

Keywords: Challenges of CBME, Competence based medical education, Faculty awareness, Faculty perspectives, Medical education. Journal of Medical Academics (2019): 10.5005/jp-journals-10070-0034

\section{INTRODUCTION}

The medical education in India is going through a radical change this year with the implementation of competency-based medical education (CBME) curriculum. The CBME is an outcome-based approach where the emphasis is on producing a competent Indian Medical Graduate (IMG). ${ }^{1}$ The salient features of the new CBME are the "competencies" that are the main focus of the curriculum. A competency can be defined as "the habitual and judicious use of communication, knowledge, technical skills, clinical reasoning, emotions, values, and reflection in daily practice for the benefit of the individual and community being served." ${ }^{2}$

The IMG is expected to be a physician of first contact who has to essay the roles of a clinician, leader, professional, communicator, and lifelong learner. The new Graduate Medical Education Regulations (GMER) states that the learning process should include living experiences, problem-oriented approach, case studies, and community health care activities. Hence, CBME is learner-centric with the teaching-learning activities concentrating on skill acquisition and clinical experiences with the didactic lectures not exceeding one-third of the schedule. Therefore, the majority of teaching schedule would include interactive sessions, practical sessions, and small group discussions.

The present curriculum is not aligned with societal needs and lays more emphasis on knowledge than skill acquisition with no formal training on attitudes. The new CBME curriculum gives priority to the doctor-patient relationship, ethical values, and the
${ }^{1-4}$ Department of Anatomy, Army College of Medical Sciences, New Delhi, India

2,3 Department of Medicine, Army College of Medical Sciences, New Delhi, India

${ }^{4}$ Department of Paediatrics, Army College of Medical Sciences, New Delhi, India

Corresponding Author: Charu Mohan, Department of Medicine, Army College of Medical Sciences, New Delhi, India, Phone: +91 9810946939, e-mail: charum88@gmail.com

How to cite this article: Rustagi SM, Mohan C, Verma N, et al. Competency-based Medical Education: The Perceptions of Faculty. J Med Acad 2019;2(1):1-5.

Source of support: The Dean and ethical committee for consent and faculty of ACMS for giving their valuable responses to the Google questionnaire

Conflict of interest: None

communication process. The development of ethical values and overall professional growth as an integral part of the curriculum shall be implemented through a structured longitudinal and dedicated program on professional development and ethics called Attitude Ethics and Communication (AETCOM). It will be delivered by well-defined modules, role plays, project work, field trips, medical camps, and voluntary services. ${ }^{1}$

One of the biggest challenges in implementing CBME would be the horizontal alignment between different subjects in a single 
phase and vertical integration across phases. This new curriculum as a system-based approach focuses on competencies that would need more efforts and dedication on the part of the faculty to make it a success. The faculty would no longer be givers of knowledge but will become facilitators in the students' acquisition of knowledge. To sensitize and train the faculty about CBME, the Curriculum Implementation Support Program (CISP) workshops are being held in various colleges across India. The aim of this study was to assess the attitude, awareness, and perception of faculty about CBME and the challenges likely to be faced in its implementation.

\section{Materials and Methods}

This study was carried out in our college as a cross-sectional questionnaire-based study. The consent of the dean and ethics committee approval were taken. The questionnaire was administered online in the form of a Google form. All faculties were sent the form through e-mail. Consenting faculty filled the form online. Responses were received from 58 faculties members. The questionnaire included both open- and closed-ended questions. It comprised of seven sections. The first part focused on the awareness and training of faculty in form of Revised Basic Course Workshops (RBCWs), AETCOM sensitization workshops, and CISP workshops. The subsequent parts had questions pertaining to awareness of faculty on FC, early clinical exposure (ECE), electives, teaching-learning methods, and assessment changes. The last section had open-ended questions to know about the likely challenges in implementation and their suggestions to make it successful. The responses were analyzed by an inbuilt Google Statistics available with Google forms.

\section{Results}

Of the 70 faculty members, 58 faculty members responded. Of the 58 faculty members who answered the questionnaire, $12.9 \%$ of faculty were not even aware that CBME is being implemented from the 2019 batch. Of the 51 faculty members who were aware of the new curriculum, only $25(43.1 \%)$ members felt that its implementation would lead to better doctors in future.

The numbers of faculty who attended the RBCW, AETCOM, and CISP workshops are given in Table 1.

Regarding the newly introduced FC, $81 \%$ of faculty were aware that such a course of 1 month was being introduced at the beginning of the new curriculum. Around $70.7 \%$ of the faculty had also seen the uploaded timetable of the FC in the college website.

Competency-based medical education has incorporated a new module of ECE, which is being introduced as a teaching tool in classroom, hospital-based, and community settings. Around $89.7 \%$ of faculty were aware that the new curriculum mandates ECE for undergraduate students. Suggestions were asked from faculty members about the cases that were more important for ECE for the fresher students. The suggestions are listed in Table 2.

The perceptions of faculty on lectures and small group teaching-learning methods are listed in Table 3. Majority of the faculty were aware that the new curriculum limits "lectures" to only one-third of the total teaching hours allotted to a particular subject and that "small group" teaching-learning methods would now account for two-third of the total teaching hours (Table 4).

Electives have been a new addition in the CBME curriculum. The new curriculum mandates 2 months of elective postings for undergraduate students between 3rd prof part-1 and part- 2 was known to $67.2 \%$ of the faculty. The topics suggested by our faculty for electives are given in Table 5.

Table 1: Number of faculty members who attended the RBCW, AETCOM, and CISP workshops

\begin{tabular}{lll}
\hline Topic & Attended $(n)$ & Not attended $(n)$ \\
\hline Revised Basic Course Workshop (RBCW) & $32(44.8 \%)$ & $26(55.2 \%)$ \\
Attitude Ethics and Communication (AETCOM) Workshop & $44(24.1 \%)$ & $14(75.9 \%)$ \\
Curriculum Implementation and Support Programme (CISP) Workshop & $35(39.7 \%)$ & $23(60.3 \%)$ \\
\hline
\end{tabular}

Table 2: Topics suggested by faculty for ECE (in random order)

\begin{tabular}{lll}
\hline Topics suggested & & \\
\hline Acute abdomen & Chest pain & Inguinal hernia \\
Myocardial infarction & Anaphylaxis & Varicose veins \\
Water-borne and food-borne disease & General fever case & Hospital-acquired and community-acquired \\
& pneumonia & Commonary tuberculosis \\
Anemia & Thyroid disorders (hyper or hypothyroidism) & disorders \\
Diabetes mellitus & Hypertension and anemia in pregnancy & Chronic renal failure \\
Hypertension & A case of ascites & Bell's palsy \\
& & Notifiable diseases under Integrated Disease \\
Malnutrition & Malaria & Wurveillance Program (IDSP) \\
Congenital heart disease & Spinal nerve injuries & Cranial nerve injuries \\
Immunization clinic & Pain abdomen & Poison ingestion \\
Dehydration & Dialysis center & Insect bites \\
Dengue & Tuberculosis & Seizure disorder \\
Gastroenteritis & Stroke & Prostate hypertrophy \\
First aid in trauma and emergency care & Pleural effusion & Paraplegia \\
Blunt injury case & Chronic liver disease & Respiratory distress \\
\hline
\end{tabular}


Table 3: Faculty responses on lectures/small group learning methods

\begin{tabular}{llll}
\hline S. no. & Question asked & Aware & Unaware \\
\hline 1 & $\begin{array}{l}\text { Are you aware that the new curriculum limits "lectures" (as a teaching-learning } \\
\text { method) to only one-third of the total teaching hours allotted to a particular subject? }\end{array}$ & $46(79.3 \%)$ & $12(20.7 \%)$ \\
2 & $\begin{array}{l}\text { Are you aware that the new curriculum mandates "small group" teaching-learning } \\
\text { methods for two-third of the total teaching hours allotted to a particular subject? }\end{array}$ & $47(81 \%)$ & $11(19 \%)$ \\
3 & Do you know of any "small group" teaching learning methods? & $42(72.4 \%)$ & $16(27.6 \%)$ \\
\hline
\end{tabular}

Table 4: Small group learning methods suggested by the faculty

\begin{tabular}{lll}
\hline Methods suggested & & \\
\hline Seminar & Tutorials & Focused group discussion \\
Fish bowl & Think pair share & Problem-based learning \\
Snow ball & Case-based discussion & Flipped classroom \\
E-Learning & Jigsaw & Role-playing \\
Buzz groups & Simulation & Bedside teaching \\
\hline
\end{tabular}

Table 5: Topics suggested for electives by faculty in random order

\begin{tabular}{ll}
\hline General elective & Clinical elective \\
\hline Statistics/biostatistics & Emergency medicine \\
Research methodology & Dialysis unit \\
Molecular techniques in diagnostics & Transfusion medicine \\
Sports/exercise physiology & Cosmetic dermatology \\
Dietetics & Psychological evaluation in pediatrics \\
Computer skills & Critical care \\
Organ donation and transplant units & Oncopathology \\
Genetics & Lab medicine \\
Hospital management & Toxicology lab \\
Assisted reproductive technology unit & Rehabilitative medicine \\
Immunology unit & Neonatology \\
Regenerative medicine & Palliative care \\
Community projects & Rheumatology \\
\hline
\end{tabular}

Table 6: Faculty awareness about assessment changes

\begin{tabular}{llll}
\hline S. no. & & Yes & No \\
\hline 1 & Are you aware that the MCl mandates regular formative assessment & 44 & 14 \\
& under CBME? & $75.9 \%$ & $24.1 \%$ \\
2 & Are you aware of the changes in weightage of internal assessment in & 34 & 24 \\
& the final result? & $(58.6 \%)$ & $(41.4 \%)$ \\
\hline
\end{tabular}

Table 7: Innovative assessment methods for formative assessment

\begin{tabular}{lll}
\hline Daily feedback & Muddiest point & Log book with reflection writing \\
Objective structured practical examination (OSPE) & One minute perceptor & Objective structured clinical examination (OSPE) \\
Mini clinical evaluation exercise (Mini-CEX) & Class quiz series & 360 degree evaluation \\
Work place based assessment (WPBA) & Portfolio & Mock case presentation \\
MCQ & Clinical encounter card & Chart simulated recall \\
\hline
\end{tabular}

The assessment methods have been modified from the previous curriculum. The responses of the awareness of the changes have been tabulated in Table 6 .

The faculty suggestions for formative assessment included the following "Innovative Assessment Methods" (Table 7).

In the last section of the questionnaire, the faculty members were also asked to give their views on the challenges faced by them. Thematic analysis of qualitative responses is given below (Table 8).

\section{Discussion}

The introduction of CBME has led to a paradigm shift in medical education across India. However, it is yet to be seen whether the promises of CBME will be able to prepare the next generation of doctors effectively to meet the health needs of the country. Faculty members across various medical colleges in India are putting in their whole-hearted efforts to make this successful. The timetable of first-year MBBS has been uploaded on the websites of respective medical colleges. 
CBME: The Perceptions of Faculty

Table 8: Thematic analysis of qualitative responses of faculty about likely challenges in CBME implementation

Inadequate number of faculty members to Logistics-related issues

implement CBME

Shortage of faculty members for small group teach- $\quad$ Required new setups in UG lab due to addition of new practicals

ing would be a major challenge

Gross mismatch between $\mathrm{MCl}$-stated faculty Lack of clinical forensic medicine cases and unpreparedness of the clinicians to share requirements in departments and actual requirement situations of medicolegal relevance and significance

to implement small group teaching and formative

assessment

Faculty to take out time from busy schedule to do the First-time exposure to a new teaching method will create hurdles

small group teaching everyday especially faculty in

clinical departments

Lack of faculty would lead to improper

implementation, conduct, and assessment

A dedicated faculty will be required to devote time

for these students

Horizontal and vertical integration of different departments

A dedicated faculty will be required to devote time for these students

Ratio of faculty and students is very less

Difficulty in the integration of all topics with other departments as the contents length differ in different departments

Training and sensitizing all faculty for the same

There should be enough cooperation between the faculty members

Logistics of conducting small groups in clinical settings in wards

Assessment and feedback for each and every activity

Piecemeal coverage of topics

Faculty to be made aware of proper guidelines

Implementation of new TL activity

As I am from FMT, and now we have to teach for 2 years and its assessment will be in the end of the course. I think they will not take seriously in first of the forensic class

Faculty to take out time from busy schedule to do the small group teaching everyday, three batches of students across three semesters with different topics going on for each semester

The teething problems of having a curriculum that fits every parallel department

It would take a lot of careful planning and execution initially but it would be fruitful in the end

Development of objective skill assessment and feedback

\begin{tabular}{ll}
\hline Procurement issues & Time-related issues \\
\hline New instruments and new kits & Time management issues \\
Required new setups in UG lab due to addition of & Syllabus completion could be a problem
\end{tabular}

new practicals

Will require better time management

Time management in imparting skills necessary

Managing teaching hours balancing already previous curriculum batches

The faculty will have to put in more number of hours to plan small group activities; for example, for case-based learning they need to draft cases for common clinical problems, so they will have to be motivated and kept free of other duties to do justice to CBME

The awareness and knowledge about the salient features and new aspects of CBME was not uniform across faculty members. Although majority of them were aware of the changes, around $10 \%$ were unaware. The new pool of faculty members joining every year have been trained in the previous curriculum and would not be aware of the finer aspects of the new curriculum. This requires that all medical institutions to keep up with the continuous efforts of updating their faculty members in form of CISPs, RBCWs, and advanced courses in medical education supported by MEU units under guidance of the $\mathrm{MCl}^{3}$

The FC as proposed by GMER has recently been concluded in most medical colleges across India. ${ }^{4}$ The FC is a 175 -hours module covered in 25 days, which includes the following components: skills module, field visit to community health center, and professional development including ethics, language, and communication skills. The students admitted to the MBBS course being from diverse backgrounds need training in local language to be able to communicate effectively with patients. Imparting basic computer skills training is also a component of FC. Eighty-one percent of our faculty were aware of the one-month $\mathrm{FC}$, and $70.7 \%$ of faculty members knew about the above-mentioned components of FC.

Early clinical exposure has been introduced in CBME to impart clinical relevance to the basic sciences. This is also expected to engrain empathy and compassion toward patients. Early clinical exposure can be in the form of case scenarios, paper cases, lab reports, ECG, photographs, and "actual patients." This can be 
imparted in the classroom setting, hospital setting, and community visits. ${ }^{1}$ Around $89.7 \%$ of the faculty members were aware that the new curriculum mandated ECE, and majority of the faculty $(86.2 \%)$ members were in agreement with the concept of exposing the first-year students to ECE.

Electives are another new introduction in the CBME curriculum. They are brief courses available to the learners to explore their interests in different medical fields consisting of one general elective and one clinical elective. They are being introduced for the first time to sensitize the students to various career options that are available after completing their graduation by having direct experiences in diverse areas. It is mandatory that all students take up any two elective topics for 2-month duration after completion of 3rd MBBS part 1 and before commencement of 3rd MBBS part-2. However, one-third of our faculty members were not even aware that the new curriculum mandates 2 months of elective postings.

Competency-based medical education enables the alignment of assessment with teaching-learning in actual workplace settings. ${ }^{5,6}$ Assessment modifications in the weightage of internal assessment as per the GMER document were known to $58.6 \%$ of our faculty members. However, the recent clarification from $\mathrm{MCl}$ states that a minimum of $40 \%$ marks are required individually in theory and practical of every subject and an aggregate of $50 \%$ score in the internal assessment is mandatory to be able to appear for summative assessment. Three-fourth (75.9\%) of the faculty members were aware about the changes in regular formative assessments under CBME.

The faculty perceives that a major challenge in implementation of CBME would be shortage of teachers for small group teaching. Presently, there is a gross mismatch between $\mathrm{MCl}$-stated faculty requirements in departments and actual numbers available in each department to implement small group teaching, early clinical exposure, electives, and formative assessment. This is more pertinent for clinical departments as their faculty members have to take time from their busy clinical schedules to do the small group teaching.
So far, CBME has been experimented in India only in few medical colleges for postgraduate education with good results but the outcome for undergraduates is awaited. ${ }^{7}$ Systematic planning needs to be done, and the approach to medical education needs to be a given a new direction. ${ }^{8}$

As faculty members are the forebearers to this new change, our study is an attempt to analyze the perceptions of the faculty and the likely challenges to be faced about the new curriculum. This knowledge can be used for proper implementation, conduct, and assessment of CBME.

\section{References}

1. Frank JR, Danoff D. The CanMEDS initiative: Implementing an outcomes-based framework of physician competencies. Med Teach 2007;29:642-647. DOI: 10.1080/01421590701746983.

2. Medical Council of India. Competency based Undergraduate curriculum for the Indian Medical Graduate. 2018. p. 37.

3. Payal B, Supe A, Sahoo S, et al. Faculty Development for Competency Based Medical Education: Global, National and Regional Perspectives. NJIRM Feb 2018;8(5):89-95.

4. Basheer A. Competency-based medical education in India: Are we ready? J Curr Res Sci Med 2019;5:1-3.

5. Levine MF, Shorten G. Competency-based medical education: Its time has arrived. Can J Anaesth 2016;63:802-806. DOI: 10.1007/s12630016-0638-6.

6. Ten Cate O, Billett S. Competency-based medical education: origins, perspectives and potentialities. Med Educ 2014;48:325-332. DOI: 10.1111/medu.12355.

7. Shrivastava SR, Shrivastava PS. Qualitative study to identify the perception and challenges faced by the faculty of community medicine in the implementation of competency-based medical education for postgraduate students. Family Medicine and Community Health 2019;7:e000043. DOI: 10.1136/fmch-2018000043.

8. Nousiainen MT, Caverzagie KJ, Ferguson PC, et al. Implementing competency-based medical education: What changes in curricular structure and processes are needed? Med Teach 2017;39:594-598. DOI: 10.1080/0142159X.2017.1315077. 